\title{
Conversion of the Seattle Angina Questionnaire into EQ-5D utilities for ischemic heart disease: a systematic review and catalog of the literature
}

This article was published in the following Dove Press journal:

ClinicoEconomics and Outcomes Research

19 May 2014

Number of times this article has been viewed

Harindra C Wijeysundera ${ }^{1-4}$

Sara Farshchi-Zarabi'

William Witteman ${ }^{5}$

Maria C Bennell'

'Schulich Heart Centre, Division of Cardiology, Sunnybrook Health Sciences Centre, ${ }^{2}$ Institute of Health Policy, Management and Evaluation, University of Toronto, ${ }^{3}$ Institute for Clinical Evaluative Sciences, ${ }^{4} \mathrm{Li}$ Ka Shing Knowledge Institute of St Michael's Hospital, Toronto, ON,

${ }^{5}$ Centre Hospitalier Universitaire du Québec, Charlesbourg, QC, Canada

Correspondence: Harindra C Wijeysundera Sunnybrook Health Sciences Centre, 2075 Bayview Avenue, Suite A202,

Toronto, ON M4N3M5, Canada

$\mathrm{Tel}+\mathrm{I} 4164804527$

Fax +I 4164804657

Email harindra.wijeysundera@ sunnybrook.ca
Background: There is a paucity of preference-based (utility) measures of health-related quality of life for patients with ischemic heart disease (IHD); in contrast, the Seattle Angina Questionnaire (SAQ) is a widely used descriptive measure. Our objective was to perform a systematic review of the literature to identify IHD studies reporting SAQ scores in order to apply a mapping algorithm to convert these to preference-based scores for secondary use in economic evaluations.

Methods: Relevant articles were identified in MEDLINE (Ovid), EMBASE (Ovid), Cochrane Library (Wiley), HealthStar (Ovid), and PubMed from inception to 2012. We previously developed and validated a mapping algorithm that converts SAQ descriptive scores to European Quality of Life-5 Dimensions (EQ-5D) utility scores. In the current study, this mapping algorithm was used to estimate EQ-5D utility scores from SAQ scores.

Results: Thirty-six studies met the inclusion criteria. The studies were categorized into three groups, ie, general IHD $(n=13)$, acute coronary syndromes $(n=4)$, and revascularization $(n=19)$. EQ-5D scores for patients with general IHD were in the range of 0.605-0.843 at baseline, and increased to $0.649-0.877$ post follow-up. EQ-5D scores for studies of patients with recent acute coronary syndromes increased from $0.706-0.796$ at baseline to $0.795-0.942$ post follow-up. The revascularization studies had EQ-5D scores in the range of $0.616-0.790$ at baseline, and increased to $0.653-0.928$ after treatment; studies that focused only on coronary artery bypass grafting increased from $0.643-0.788$ at baseline to $0.653-0.928$ after grafting, and studies that focused only on percutaneous coronary intervention increased in score from $0.616-0.790$ at baseline to $0.668-0.897$ after treatment.

Conclusion: In this review, we provide a catalog of estimated health utility scores across a wide range of disease severity and following various interventions in patients with IHD. Our catalog of EQ-5D scores can be used in IHD-related economic evaluations.

Keywords: health-related quality of life, Seattle Angina Questionnaire, utilities, European Quality of Life-5 Dimensions, mapping algorithm, ischemic heart disease

\section{Introduction}

Economic evaluations with cost-effectiveness analyses are important in the decisionmaking process for health resource allocation. Cost-effectiveness analysis involves estimation of the incremental cost of a new intervention as well as its incremental net health benefit, in comparison with a reference. To facilitate the comparison of different interventions, it is important that the health effects be reported in standardized units. Current guidelines recommend that the metric of choice for reporting health benefits in cost-effectiveness analysis is the quality-adjusted life-year. ${ }^{1-5}$ 
A variety of techniques have been developed to assess patient quality of life. Available instruments can be generally classified into two major categories, ie, descriptive measurement instruments or preference-based methods. Descriptive measurement instruments are designed to measure quality of life across important aspects of a patient's health state, such as physical, psychosocial, or functional well-being. ${ }^{6}$ Such instruments provide a score for each health domain and a quantitative measure that represents a patient's current health state. In contrast, preference-based or utility instruments, such as the European Quality of Life-5 Dimensions (EQ-5D), add a valuation component to a patient's reported health state. ${ }^{7}$ These instruments are designed to reflect both a quantitative description of a patient's health state and society's preference for that particular health state. This preference component is the primary distinction between a utility instrument and a descriptive measurement instrument. Preference-based instruments allow for the calculation of quality-adjusted life-years.

In ischemic heart disease (IHD) research, there is an abundance of published literature on the Seattle Angina Questionnaire (SAQ), a descriptive quality of life instrument. The SAQ is a validated descriptive instrument that evaluates quality of life in patients with IHD across five domains, specifically physical limitation, treatment satisfaction, angina frequency, angina stability, and disease perception. ${ }^{8}$ In contrast, there is a paucity of studies that report utility weights for patients with IHD. ${ }^{3}$ The absence of available and up-to-date utility weights is a substantial limitation when performing economic analyses in IHD. To address this lack of utility information, we have previously published a mapping algorithm to convert SAQ descriptive scores to utility weights, based on the EQ-5D preference-based utility instrument. ${ }^{9,10}$

In this study, we extended our previous work by performing a systematic review of the literature to identify all previous studies that used the SAQ to measure health state, and then applied our validated mapping algorithm to create a comprehensive catalog of utility weights across the spectrum of IHD, with the intention that our catalog be used for future economic evaluations in IHD.

\section{Materials and methods Search strategy}

First, we conducted a systematic review of the published literature, conforming to the standards recommended by the PRISMA (Preferred Reporting Items for Systematic Reviews and Meta-Analyses) guidelines. ${ }^{11}$ We used the search terms "Seattle Angina Questionnaire", "SAQ", or slight modifica- tions of these terms (see Supplementary material for full search strategy) to identify potentially relevant citations from inception to November 7, 2012 using the following medical literature databases: MEDLINE (Ovid), EMBASE (Ovid), Cochrane Library (Wiley), HealthStar (Ovid), and PubMed. We subsequently performed a citation search in Google Scholar (Google), Web of Science (Thomson Reuters), and Scopus (Elsevier) to identify articles citing the original paper by Spertus et $\mathrm{al}^{8}$ that first examined the validity and reliability of the SAQ. Finally, we searched major clinical trial registries (clinicaltrials.gov and clinicaltrialsregister.eu) from inception to November 7, 2012 for studies that used the SAQ as an outcome measure, using the search terms "Seattle Angina Questionnaire" or "SAQ".

Upon removal of duplications, two independent reviewers (SF and HCW) screened each reference. We utilized a hierarchal approach, screening citations by title, then abstract, and finally by full text to determine relevance. Reviewers assessed the eligibility of these selected articles according to two prespecified inclusion criteria, ie, that publication was in English and that mean scores and standard errors (or the ability to calculate standard errors from the available data) were reported for all five domains of the SAQ. Although the SAQ has been translated into multiple languages, the original SAQ validation studies were based on the English version; as such, we restricted our algorithm to English articles. All five domains were needed to utilize our mapping algorithm. Exclusion criteria were articles that reported on experimental interventions (eg, transmyocardial laser revascularization, herbal medicine) that are not part of standard therapy. The following information was extracted from eligible studies: baseline characteristics of study participants (age, gender); inclusion and exclusion criteria for each study, interventions (eg, myocardial infarction, revascularization) and follow-up duration; and reported SAQ scores and standard errors.

\section{Data synthesis}

We have previously created and published a prediction algorithm using multivariable linear regression modeling, with the utility weight from the EQ-5D being our response variable of interest. Details of the derivation and validation of the mapping algorithm are available elsewhere. ${ }^{9}$ In brief, all model fitting was done using Bayesian methods. The posterior probability distribution for each of the model parameters was estimated using Markov Chain Monte Carlo simulation methods, with noninformative prior distributions for all model parameters. The data for model development 
were from 1,992 consecutive patients who underwent coronary angiography in 2004 as part of the Alberta Provincial Project for Outcome Assessment in Coronary Heart Disease database. The final mapping algorithm was a linear regression model, with the dependent variable being the EQ-5D, and a conditional distribution of $\mathrm{Y}_{\mathrm{i}} \sim \mathrm{N}\left(\mu_{\mathrm{i}}, \sigma_{\mathrm{i}}\right)$. The specification of the mean was given by:

$$
\mu_{i}=\beta_{0}+\beta_{1} A_{i}+\beta_{2} A_{i}+\beta_{3} D_{i}+\beta_{4} P_{i}+\beta_{5} T_{i}
$$

with the following parameter estimates:

intercept $0.4388(0.4015-0.4763), \beta$ AF 0.0010 (0.0007-0.0013), $\beta$ AS -0.0002 ( -0.0005 to 0.0000$), \beta$ DP 0.0023 (0.0020-0.0027), $\beta$ PL 0.0019 (0.0017-0.0022), $\beta$ TS 0.0004 ( -0.0001 to 0.0008$)$.

Using the posterior distribution for the coefficients of the final linear regression mapping algorithm, we calculated the EQ-5D based on the scores for the five SAQ domains for each included study. To fully incorporate uncertainty in the estimated EQ-5D utilities, we assumed that the inputted SAQ values from each paper had a normal distribution, based on the mean and standard error. We sampled from this distribution to calculate the mean and $95 \%$ credible interval of the estimated EQ-5D.

The mapping algorithm and EQ-5D estimates were calculated using WinBUGS version 1.4 (Medical Research Council, London, UK).

\section{Results}

\section{Study selection}

We identified 2,776 citations from various sources using our search criteria. After removing duplications, 1,092 articles were screened to identify articles in English that were potentially relevant and that reported scores and standard errors (or standard deviation and sample size, or confidence intervals, in order to calculate the standard error) for all five domains of the SAQ. Full review was done on 60 articles. We excluded 24 of these articles because they provided SAQ scores following experimental interventions, ie, neurostimulation (six articles), autologous bone marrow transplant (three articles), transmyocardial laser revascularization (six articles), herbal medicine (two articles), fibroblast growth factor (one article), granulocyte colony-stimulating factor (one article), cognitive behavioral therapy (one article), and other (four articles). A total of 36 articles met our eligibility criteria and were included in the final analysis. Figure 1 presents the flow diagram of our review process.

\section{Study characteristics}

The 36 studies in our systematic review represent a wide spectrum of patients with IHD. Eight of these studies focused exclusively on patients with stable angina, ${ }^{12-19}$ and four included patients with a previous myocardial infarction. ${ }^{12,20-22}$ Four studies specifically assessed SAQ in patients with advanced IHD unsuitable for revascularization. ${ }^{18,23-25}$ These studies reported SAQ scores in patients with general angina, or specifically with severe or refractory angina. Five studies were restricted to an elderly population, ${ }^{23,26-29}$ one study was restricted to women with IHD, ${ }^{30}$ and one study reported SAQ data in diabetic patients with IHD. ${ }^{17}$ SAQ data were compared among South Asians versus Europeans with IHD in one study, ${ }^{31}$ while another study reported the SAQs of Caucasians and African Americans with IHD. ${ }^{20}$ The studies ranged from cross-sectional evaluations with no follow-up to longitudinal studies with follow-up ranging from 7 days to a mean of 6 years and 11 months.

Given our intent to form a catalog such that estimated utility scores can be easily referenced, we categorized the 36 included articles in three groups, as shown in Tables 1-3. Thirteen studies focused on general IHD patients (Table 1), four focused on patients with recent acute coronary syndrome (Table 2), and 19 assessed revascularized patients (Table 3), of which eight included only patients who underwent coronary artery bypass grafting $(\mathrm{CABG})^{23,28,29,32-36}$ and six included only patients who had percutaneous coronary intervention. ${ }^{19,21,27,37-39}$

\section{Predicted EQ-5D}

The SAQ scores from the original publications and the calculated EQ-5D scores are shown in Tables 1-3. The estimated baseline EQ-5D scores for the general IHD patients were in the range of $0.605-0.843$, increasing to $0.649-0.877$ post follow-up (Table 1). The baseline range was $0.706-0.796$ for the studies focused on patients with a recent acute coronary syndrome, increasing to $0.795-0.942$ post follow-up (Table 2). The revascularization studies had EQ-5D scores in the range of 0.616-0.790 at baseline, increasing to 0.653-0.928 after treatment (Table 3). Studies that included only CABG as the revascularization modality had an EQ-5D score range that increased from $0.643-0.788$ at baseline to $0.653-0.928$ after CABG; the studies that focused only on percutaneous coronary intervention had scores that increased from $0.616-0.790$ at baseline to $0.668-0.897$ after treatment.

\section{Discussion}

In this report, we have provided a comprehensive catalog of predicted EQ-5D utility scores for patients with IHD. We first 


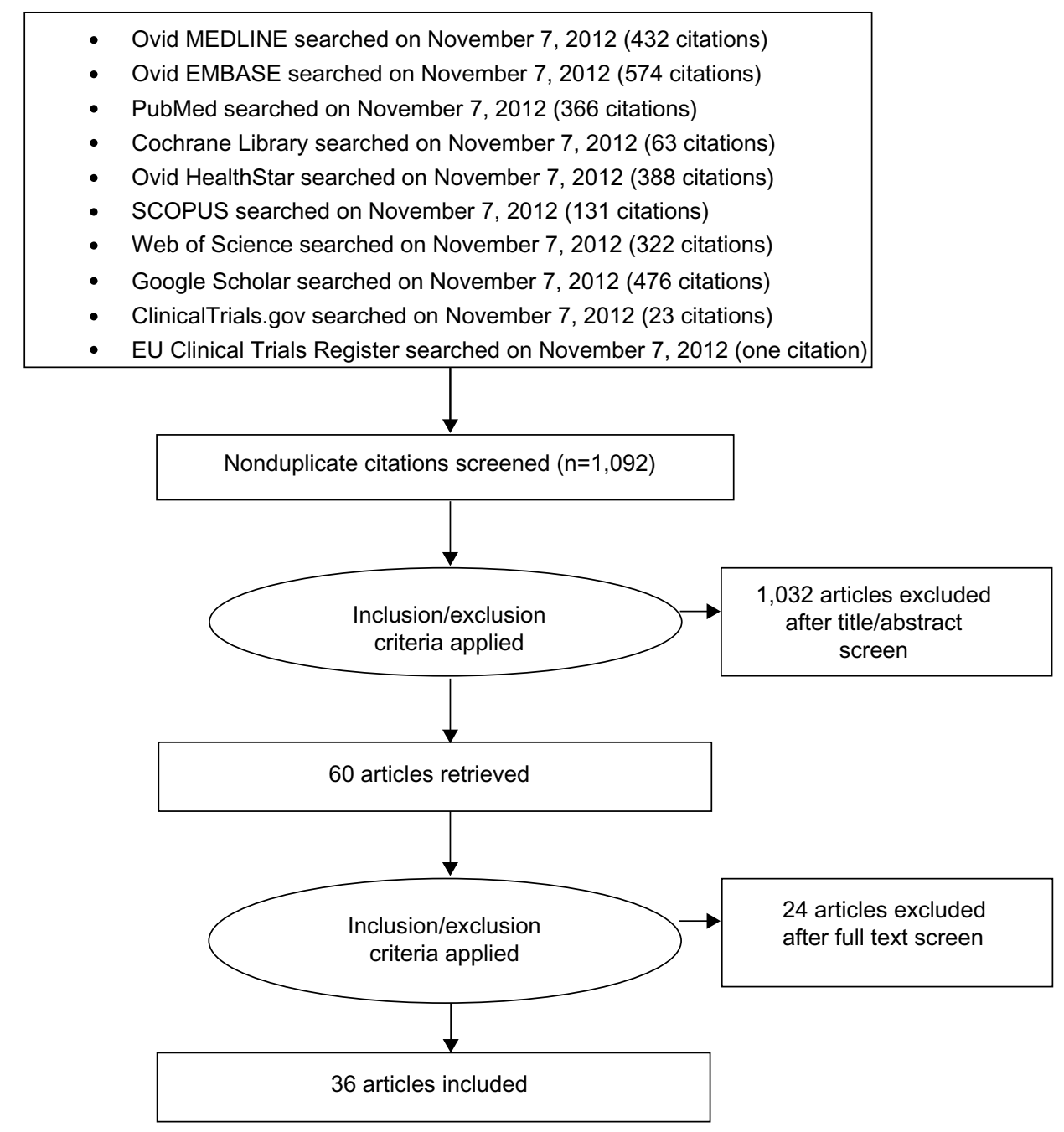

Figure I Process of study selection.

performed a systematic review of the literature to identify studies that reported SAQ scores and then applied our previously validated mapping algorithm to convert SAQ scores to EQ-5D scores. The studies included in our systematic review represent a broad spectrum of IHD patients and assessed quality of life at baseline and/or following a broad range of nonpharmacologic, medical, or surgical interventions.

Patient-reported health status has gained an increasingly important role in the decision-making process for health resource allocation. ${ }^{40}$ Patient health status independently predicts mortality, cardiovascular events, hospitalizations, and costs of care in cardiovascular illnesses. ${ }^{41-43}$ Current methodologic guidelines emphasize the importance of preference-based measures in comparative effectiveness studies of health technologies. For example, the National Institute for Health and Clinical Excellence suggests that EQ-5D is the preferred method in quantifying the health outcome of various interventions ${ }^{44}$ However, in many circumstances, preference-based instruments have not been included in cardiovascular studies. In the absence of such information, mapping techniques such as that applied in the current study can be used to estimate utility weights from available descriptive quality of life data. ${ }^{45}$

Dyer et al recently published a summary of available EQ-5D scores from the entire spectrum of cardiovascular diseases ${ }^{46}$ and were able to identify 18 studies in IHD. They observed significant heterogeneity in the reported EQ-5D scores across these studies, in the range of $0.45-0.88$. We believe our study is an important addition to this early work, by providing utility scores on additional studies in IHD, covering a wide spectrum of revascularization modalities and patient populations. Similar to the previous work by Dyer et al, we found heterogeneity between studies. This heterogeneity in utility weights between studies underscores the importance of a catalog such as ours. When researchers are developing economic models, it is essential that the 


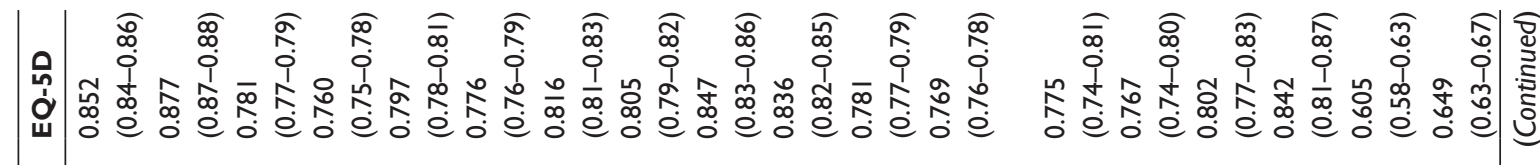

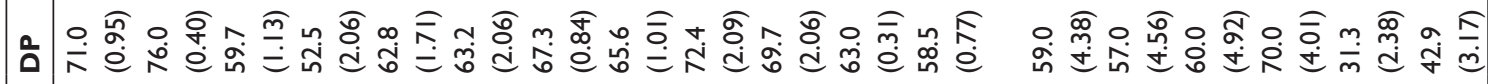

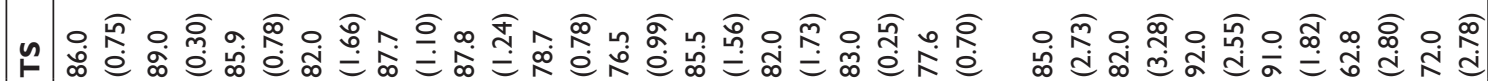

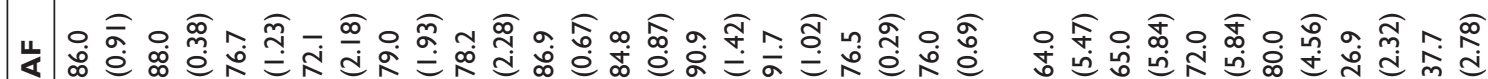

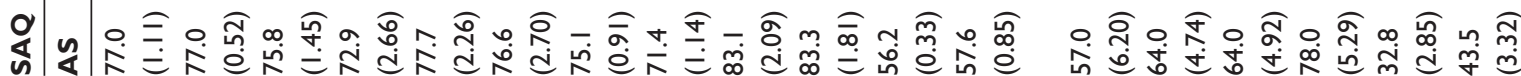

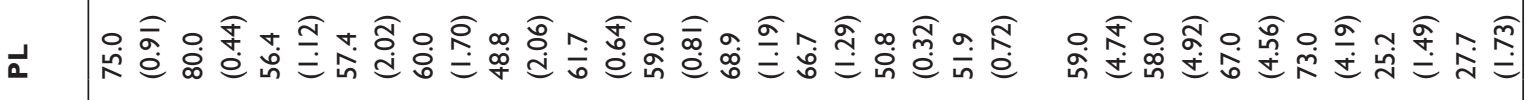

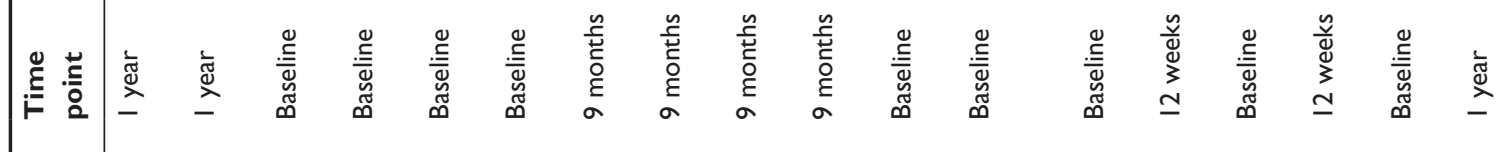

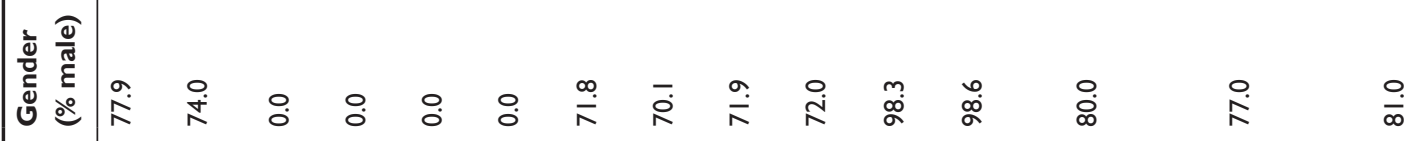

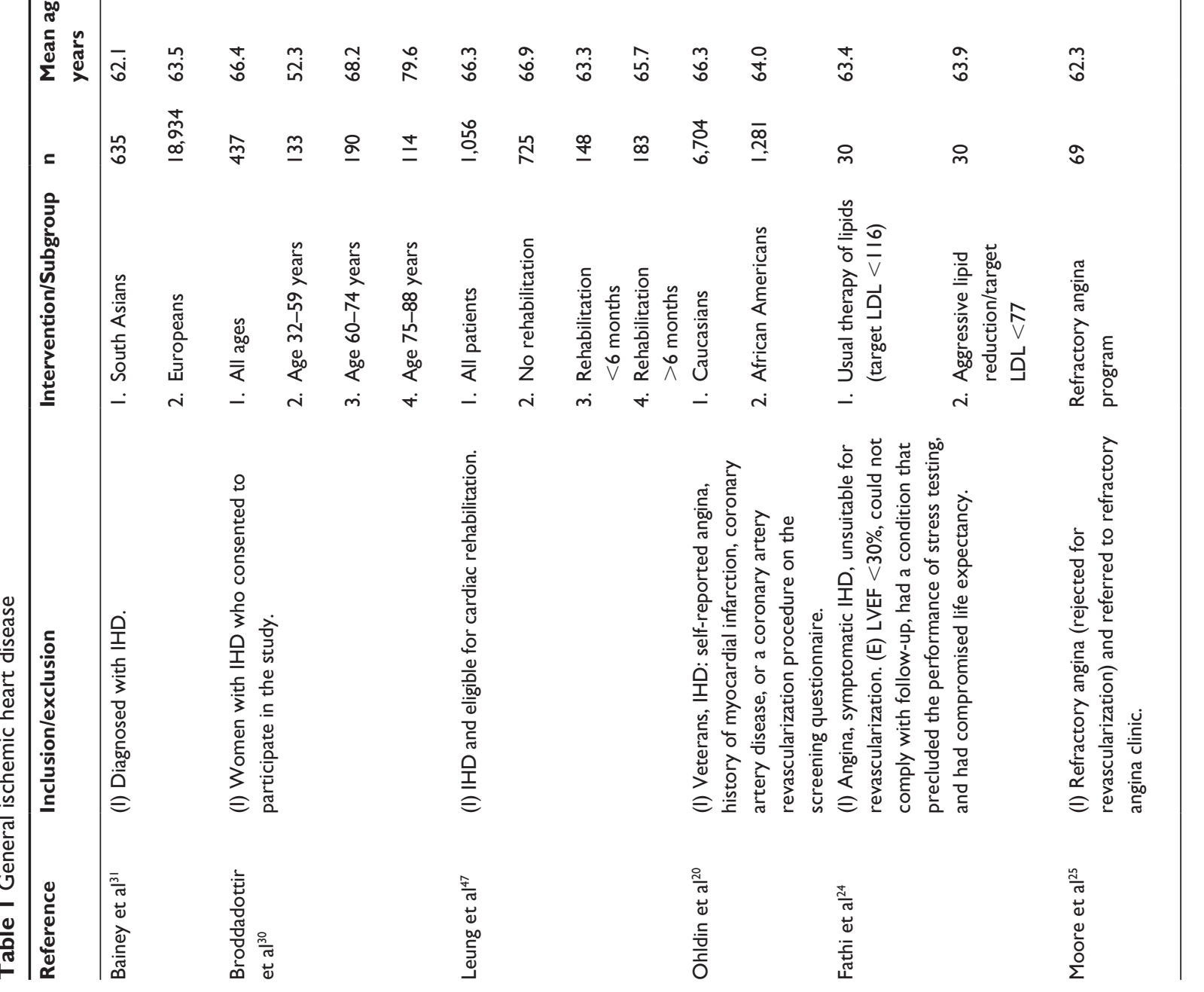




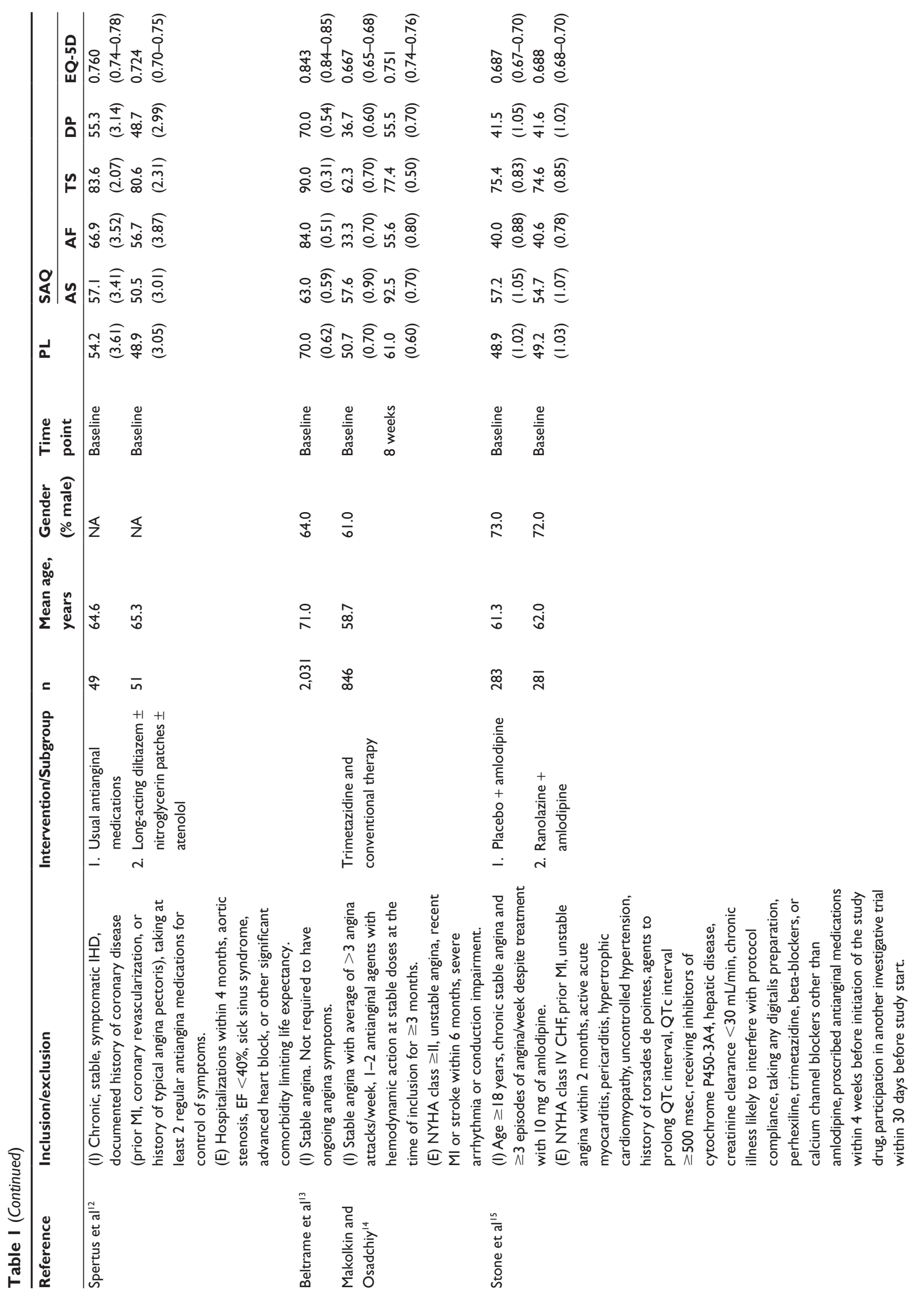




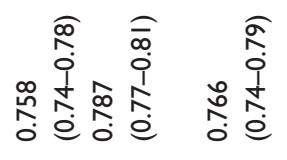

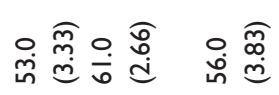

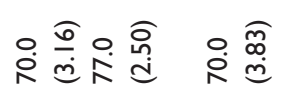

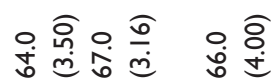

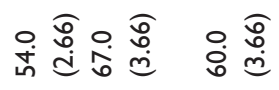

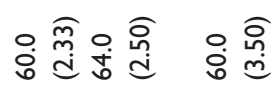

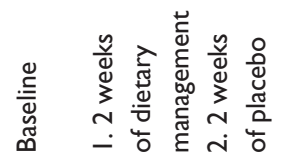

$\stackrel{\infty}{N}$

นู่

m

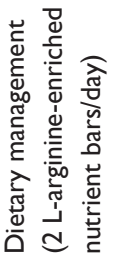

实

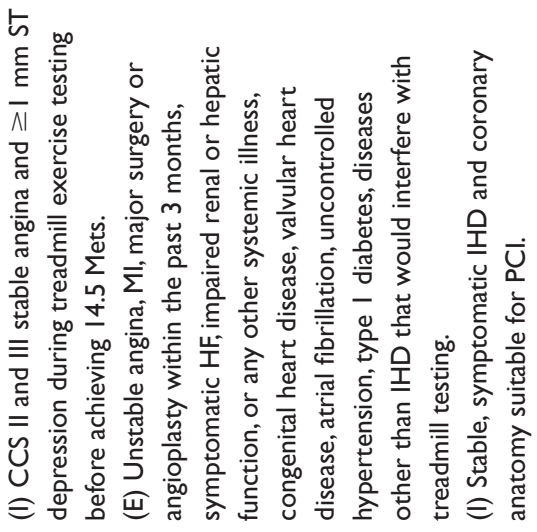

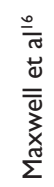

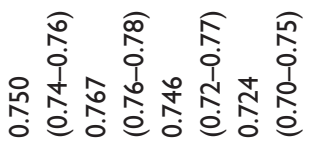

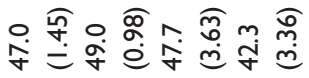

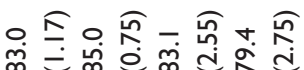

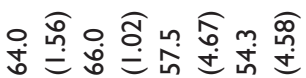

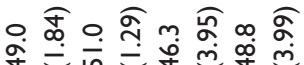

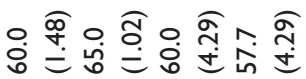

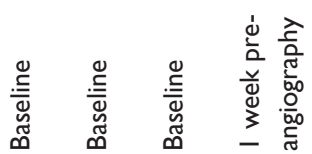

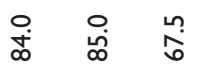

กํ

이 ๙ิ

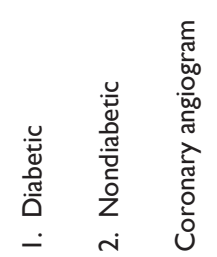

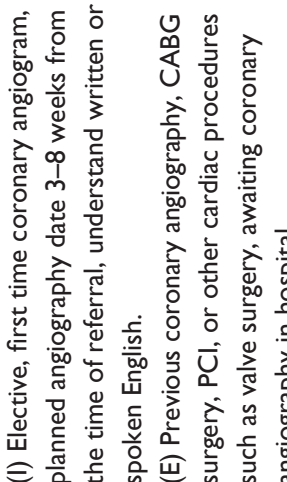

术

产这它

究

ż o

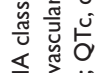

乙돈

은

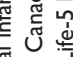

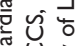

है 步

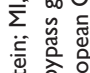

훙존

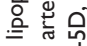

즐 정여

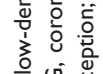

今这

흔

要这

을

害

焉

娄

崖

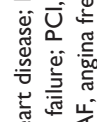

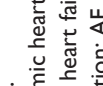

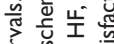

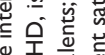

巡

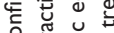

운

๙ू. छู

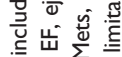

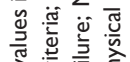

>

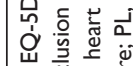

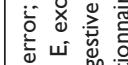

गु

洁岌岌

은

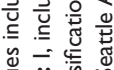

过 茊

告

尔票。文

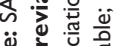




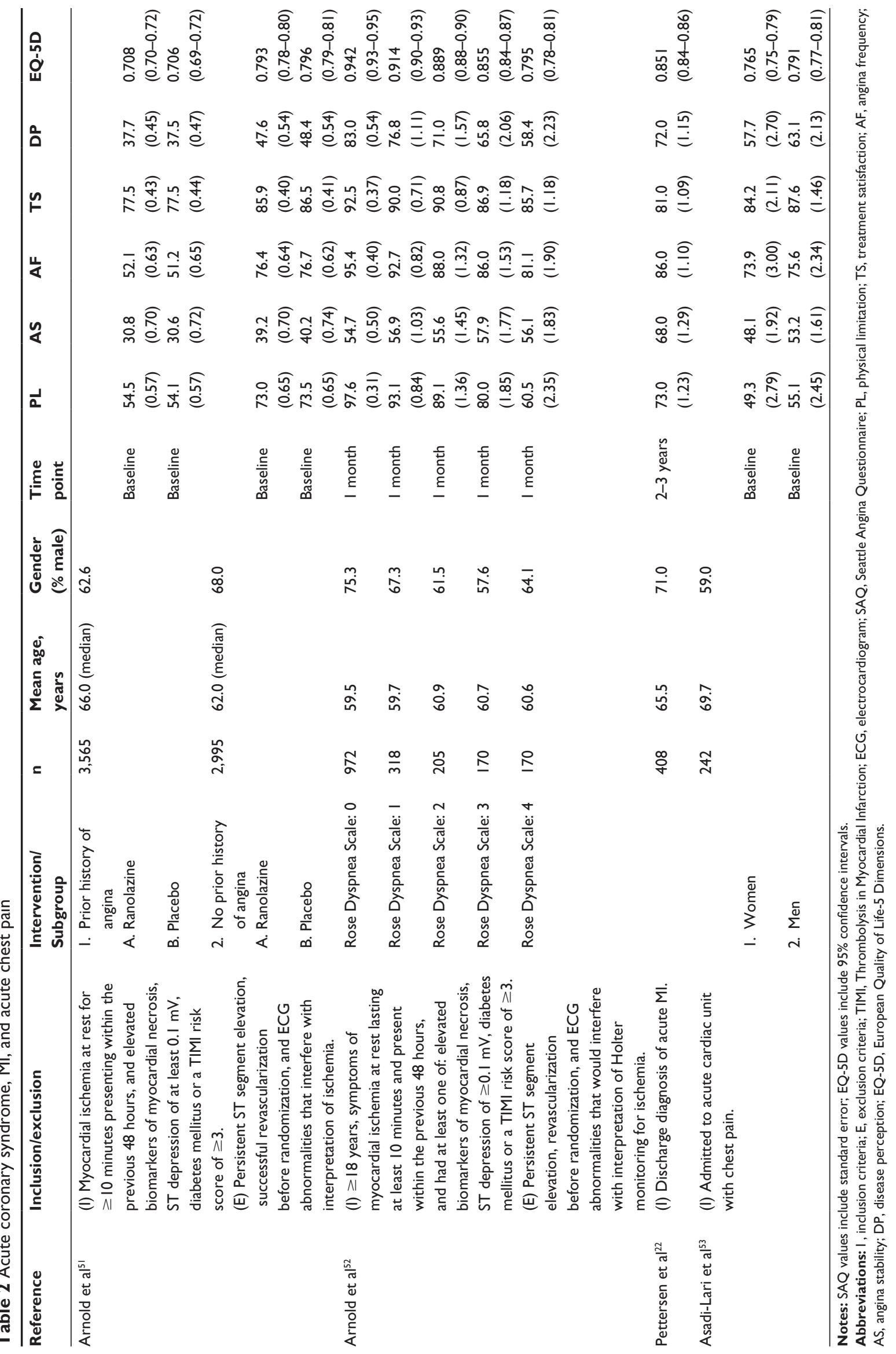




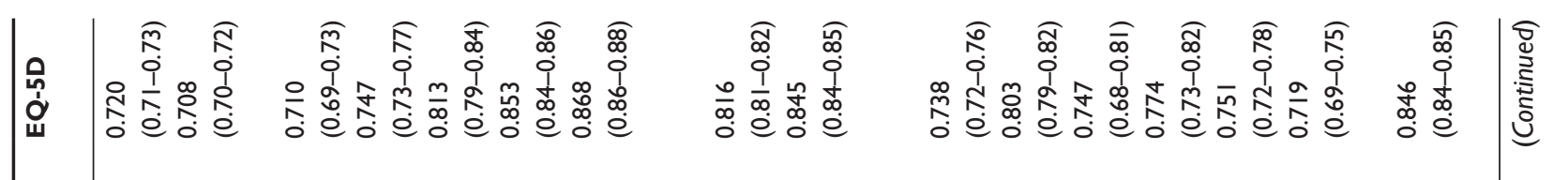

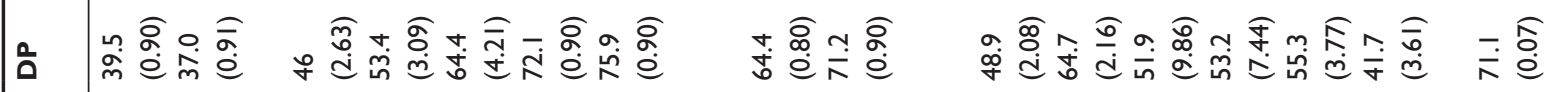

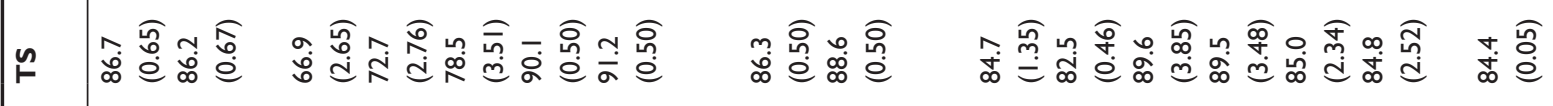

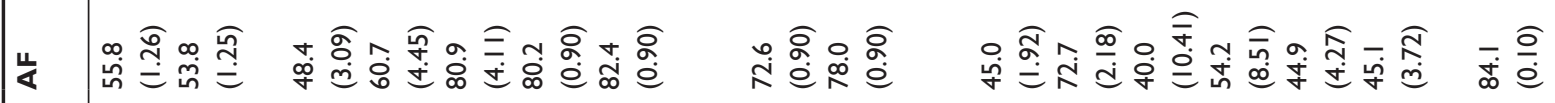

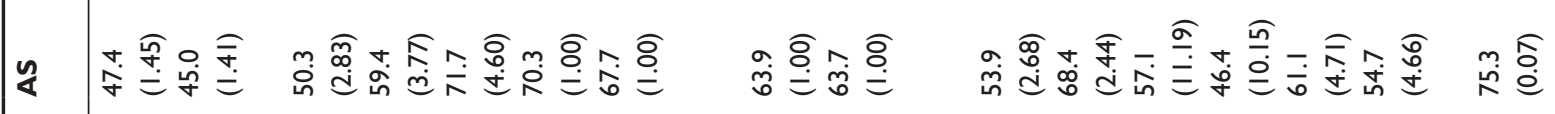

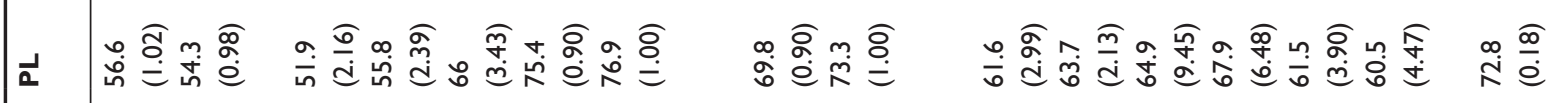

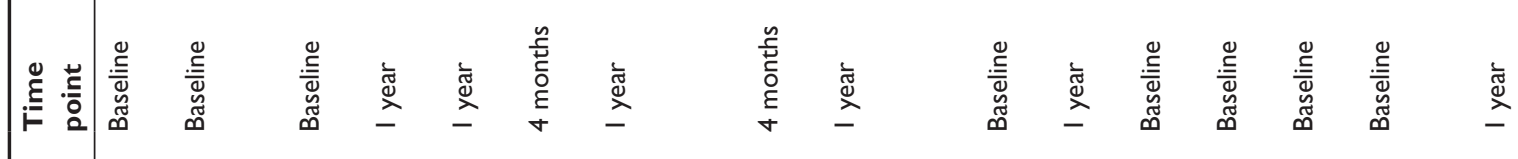

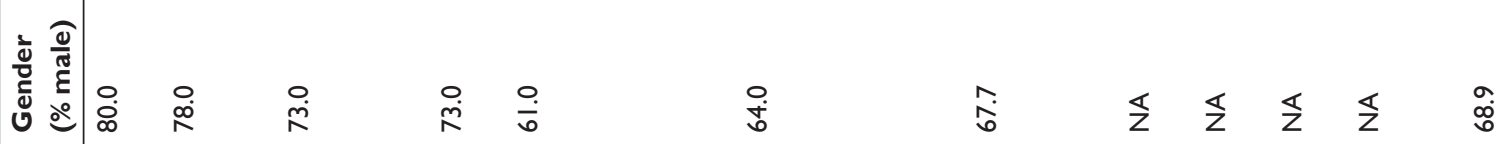

总

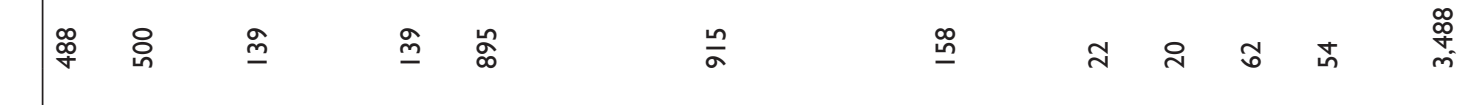

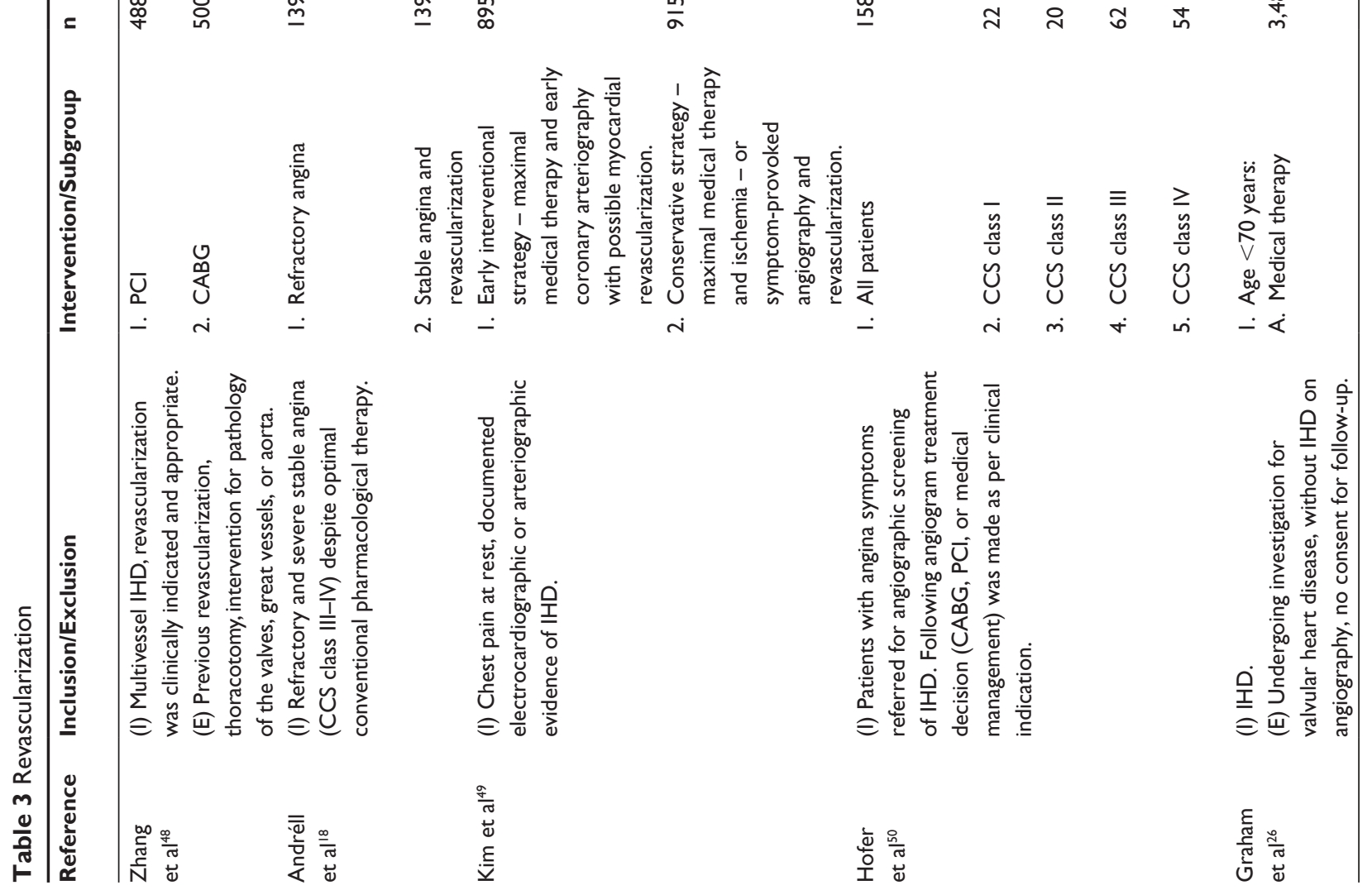




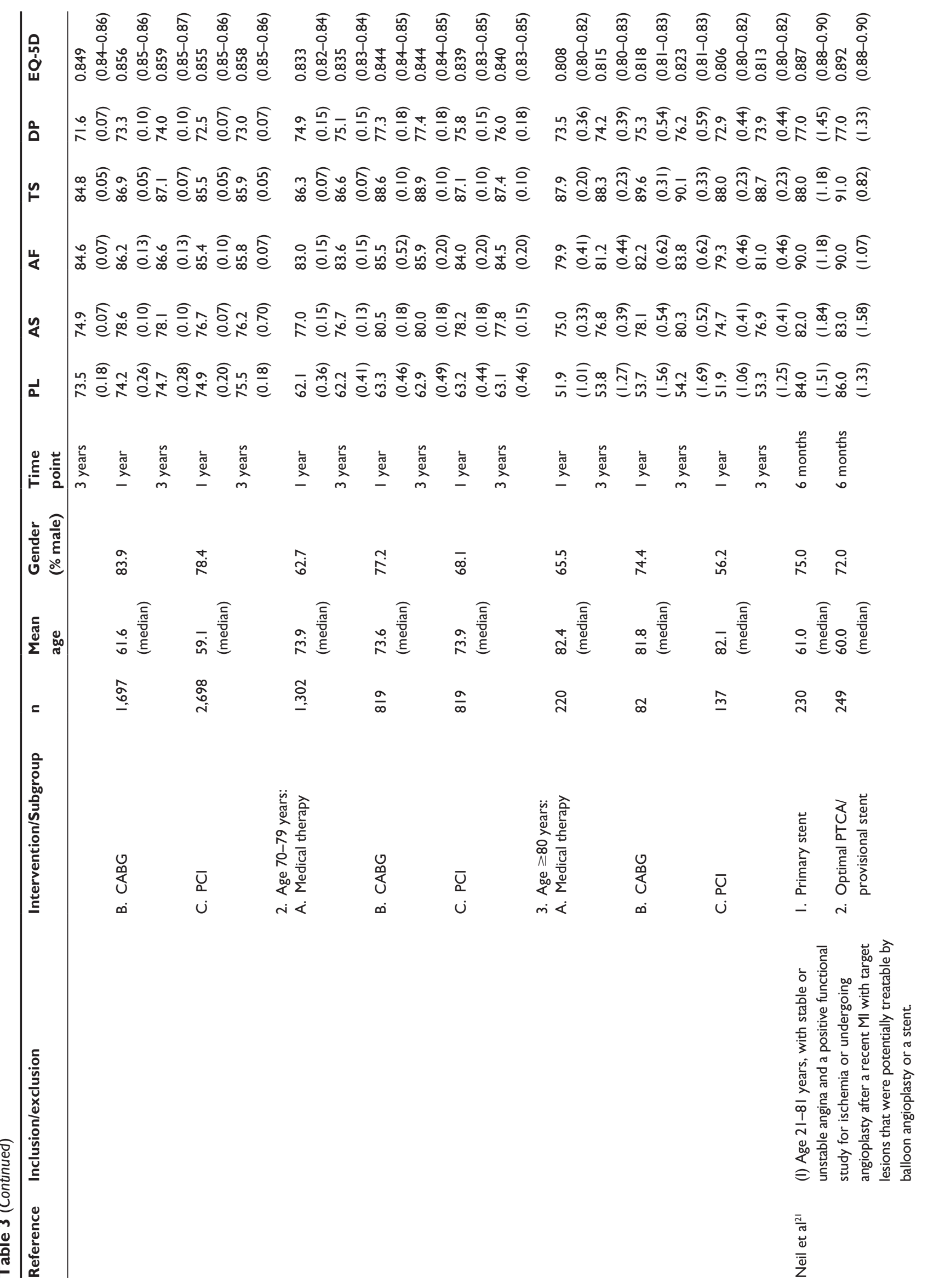




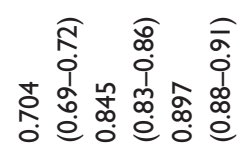

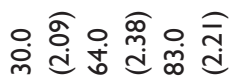

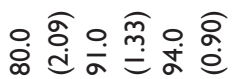

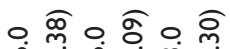

ம்

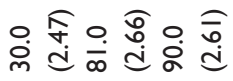

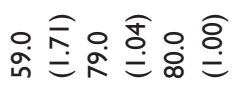

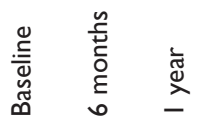

o

$\stackrel{\infty}{i}$

으

$\bar{\square}$

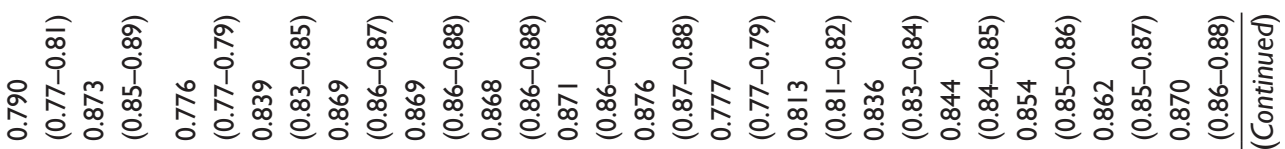

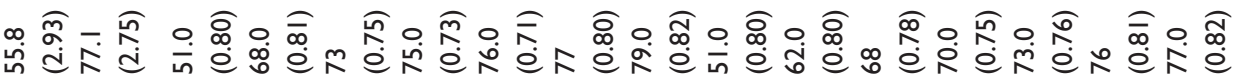

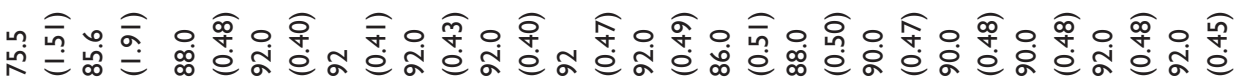

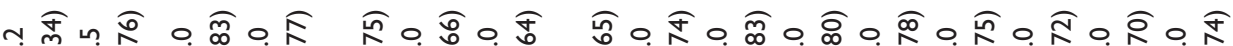

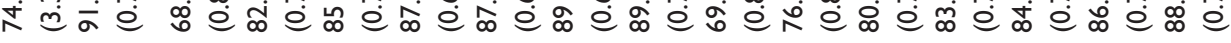

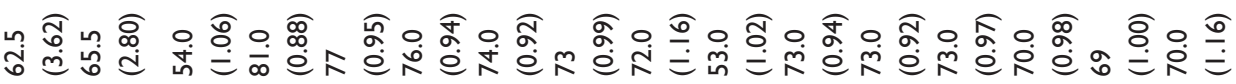

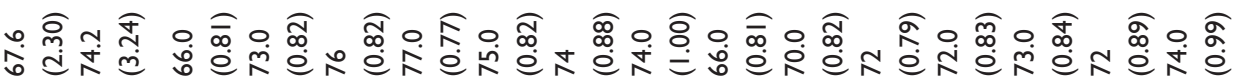

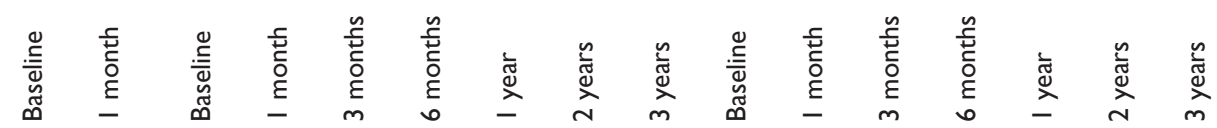

药品

$\stackrel{\circ}{\infty}$

용

$\stackrel{\infty}{\circ}$

$\stackrel{\infty}{\stackrel{m}{=}}$

$\stackrel{5}{0}$
+
$\overline{0}$
$\stackrel{-}{+}$ $\sum_{0}^{\circ}$

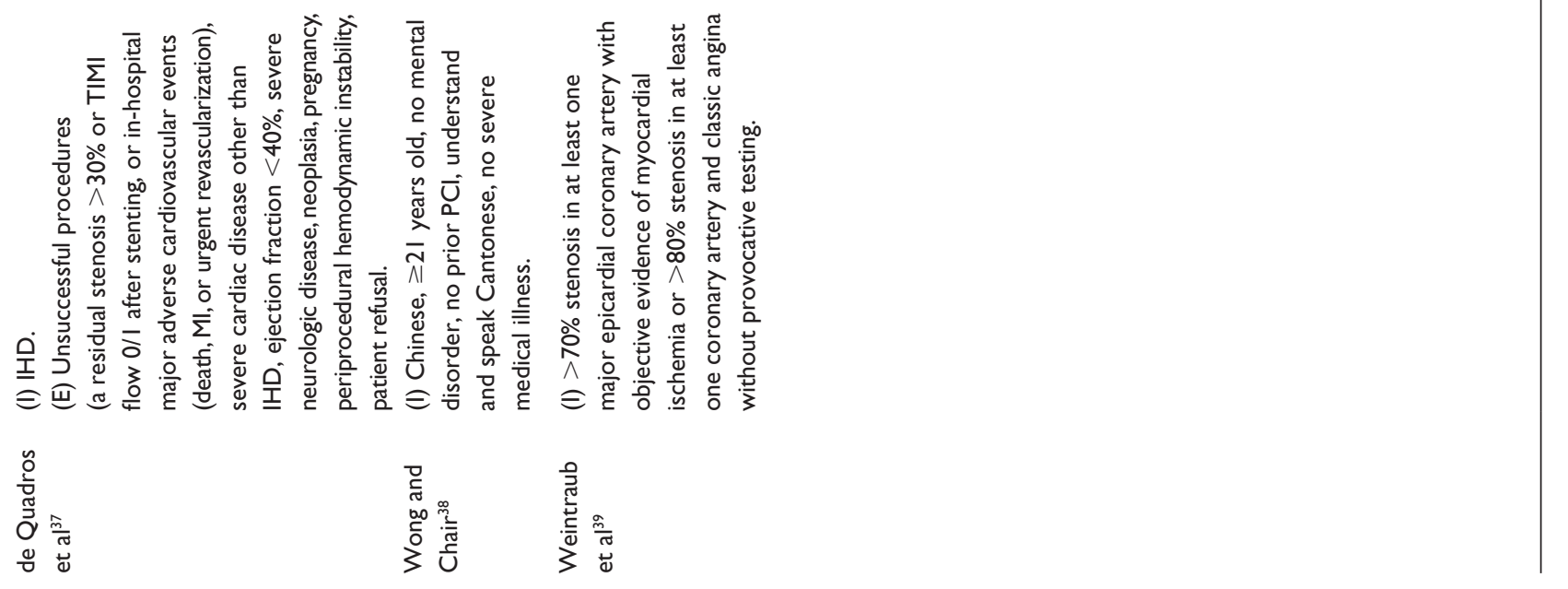




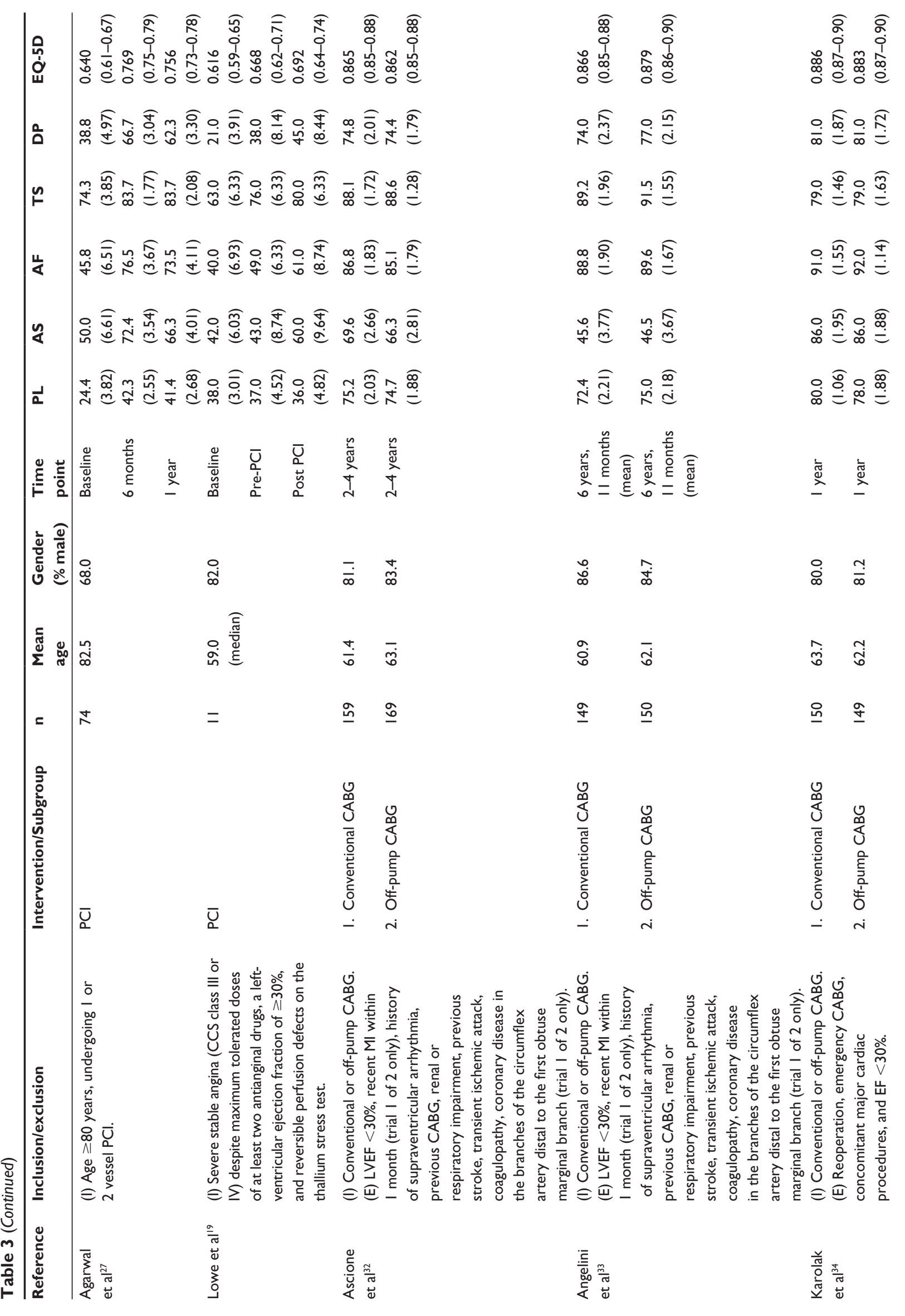




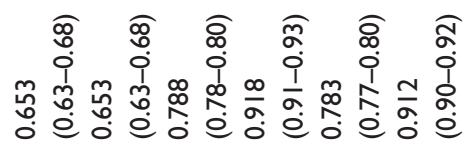

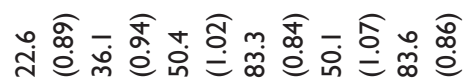

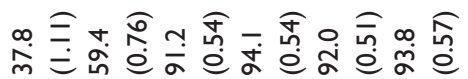

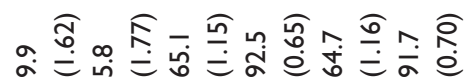

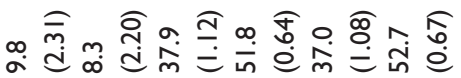

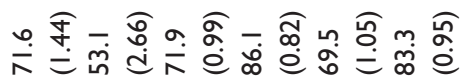

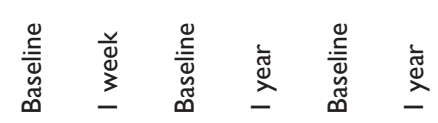

용 용

이 이 웅

○

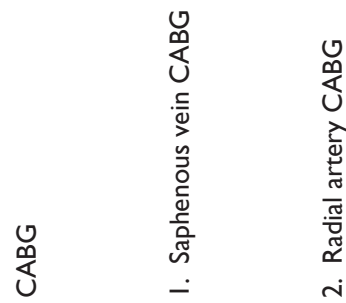

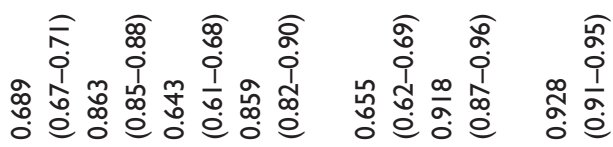

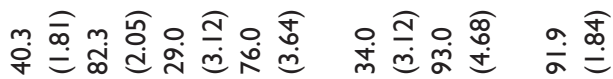

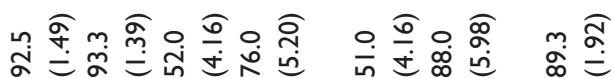

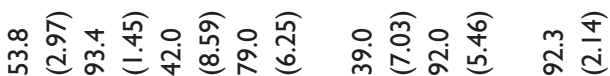

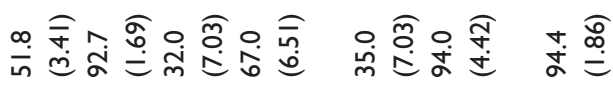

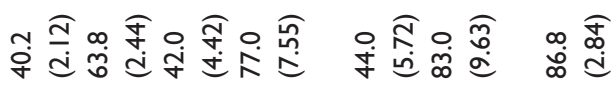

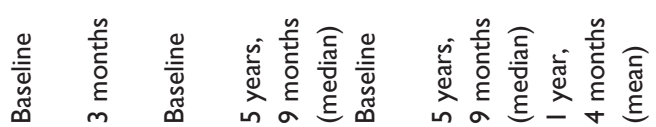

$\begin{array}{llll}\circ & \circ & \circ & \circ \\ 0 & 0 & 0\end{array}$

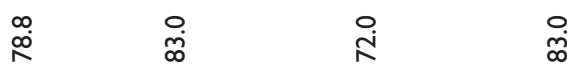

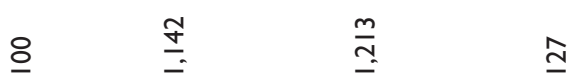

ত্ৰ

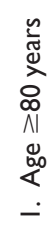

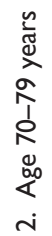

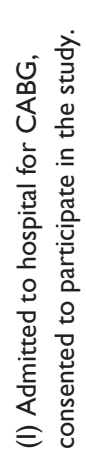
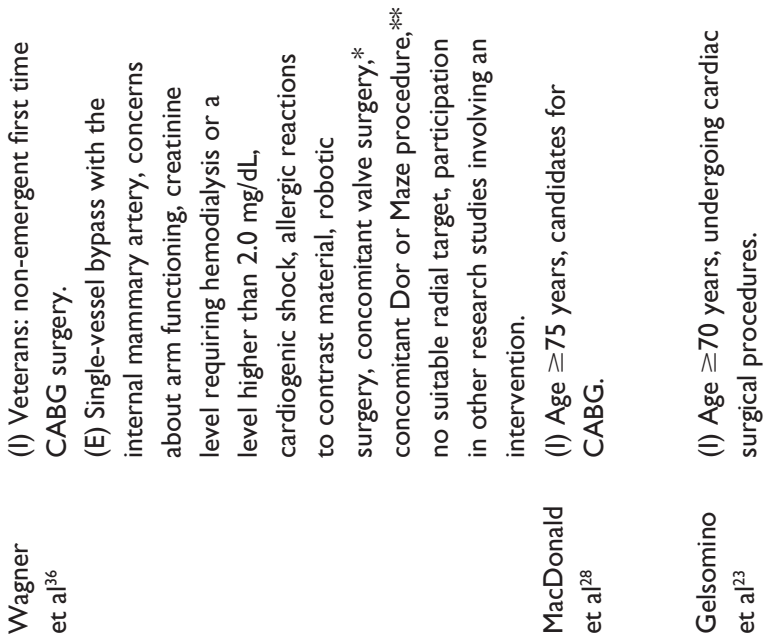

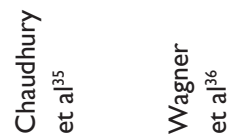

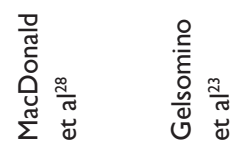

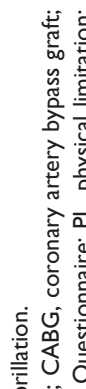

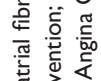

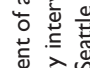

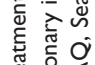

过

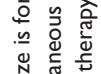

$\sum$ 宩

ㅎㅎㅁ늠

高 煺

*..

产旁占

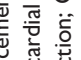

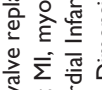

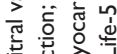

E

흔든

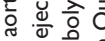

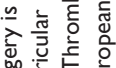

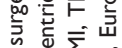

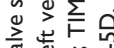

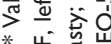

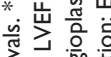

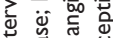

要

政

它

娲

임

害

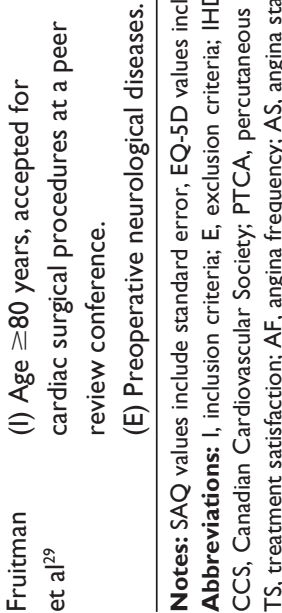


utility weights inputted are reflective of the population being studied. Our catalog provides detailed information on the population being evaluated, as well as interventions, which will provide researchers with the information needed such that they can utilize the most appropriate utility weights when developing economic models.

Our mapping algorithm was designed to estimate EQ-5D scores using the scores and standard errors in all five domains of the SAQ. ${ }^{9}$ An important limitation is that we had to exclude studies that did not publish scores on all five domains of the SAQ. However, our final catalog included estimated EQ-5D scores across a wide range of baseline patient demographics, disease severity, and various treatment interventions. A weakness of our systematic review is that we failed to capture studies that did not use the name of the SAQ scale in the text of the paper and failed to cite the source of the questionnaire.

In conclusion, in the current era of budgetary constraints, cost-effectiveness analysis has become increasingly important in decision-making for health resource allocation. In the absence of directly measured individual patient preference-based data, our catalog of estimated EQ-5D scores can be useful in IHD-related economic evaluations.

\section{Acknowledgment}

HCW is supported by a Distinguished Clinical Scientist Award from the Heart and Stroke Foundation of Canada.

\section{Author contributions}

$\mathrm{HCW}$ was involved in the conception, design, acquisition, analysis and interpretation of the data, and critically revised the manuscript. SFZ was involved in the conception and design, acquisition of data, and interpretation of the data, and drafted the manuscript. WW was involved in conception of the study, performed the systematic search, and revised the manuscript critically. MCB was involved in the acquisition of data, analysis and interpretation of data, and revised the manuscript critically. All authors approved the final manuscript for publication and agree to be accountable for all aspects of the work.

\section{Disclosure}

The authors report no competing interests in this work.

\section{References}

1. National Institute for Health and Clinical Excellence. Guide to the Methods of Technology Appraisal. London, UK: National Institute for Clinical Excellence; 2004.
2. Canadian Agency for Drugs and Technologies in Health. Guidelines for the Economic Evaluation of Health Technologies: Canada. 3rd ed. Ottawa, ON, Canada: Canadian Agency for Drugs and Technologies in Health; 2006.

3. Longworth L, Buxton M, Sculpher M, Smith D. Estimating utility data from clinical indicators for patients with stable angina. Eur J Health Econ. 2005;6(4):347-353.

4. World Health Organization. Making Choices in Health: WHO Guide to Cost-Effectiveness Analysis. Geneva, Switzerland: World Health Organization; 2003.

5. Drummond MF, Sculpher MJ, Torrance GW, O'Brien BJ, Stoddart GL. Methods for the Economic Evaluation of Health Care Programmes. 3rd ed. Oxford, UK: Oxford University Press; 2005.

6. Llewellyn-Thomas HA. Health state descriptions. Purposes, issues, a proposal. Med Care. 1996;34(Suppl 12):DS109-DS118.

7. Dolan P. Modeling valuations for EuroQol health states. Med Care. 1997;35(11):1095-1108.

8. Spertus JA, Winder JA, Dewhurst TA, et al. Development and evaluation of the Seattle Angina Questionnaire: a new functional status measure for coronary artery disease. J Am Coll Cardiol. 1995;25(2): 333-341.

9. Wijeysundera HC, Tomlinson G, Norris CM, Ghali WA, Ko DT, Krahn MD. Predicting EQ-5D utility scores from the Seattle Angina Questionnaire in coronary artery disease: a mapping algorithm using a Bayesian framework. Med Decis Making. 2011;31(3):481-493.

10. Brooks R. EuroQol: the current state of play. Health Policy. 1996;37(1):53-72.

11. Moher D, Liberati A, Tetzlaff J, Altman DG. Preferred reporting items for systematic reviews and meta-analyses: the PRISMA statement. Ann Intern Med. 2009;151(4):264-269.

12. Spertus JA, Dewhurst T, Dougherty CM, Nichol P. Testing the effectiveness of converting patients to long-acting antianginal medications: the Quality of Life in Angina Research Trial (QUART). Am Heart J. 2001;141(4):550-558.

13. Beltrame JF, Weekes AJ, Morgan C, Tavella R, Spertus JA. The prevalence of weekly angina among patients with chronic stable angina in primary care practices: the Coronary Artery Disease in General Practice (CADENCE) Study. Arch Intern Med. 2009;169(16): 1491-1499.

14. Makolkin VI, Osadchiy KK. Trimetazidine modified release in the treatment of stable angina: TRIUMPH studyTRImetazidine MR in patients with stable angina: unique metabolic PatH. Clin Drug Investig. 2004;24(12):731-738.

15. Stone PH, Gratsiansky NA, Blokhin A, Huang IZ, Meng L; ERICA Investigators. Antianginal efficacy of ranolazine when added to treatment with amlodipine: the ERICA (Efficacy of Ranolazine in Chronic Angina) trial. J Am Coll Cardiol. 2006;48(3):566-575.

16. Maxwell AJ, Zapien MP, Pearce GL, MacCallum G, Stone PH. Randomized trial of a medical food for the dietary management of chronic, stable angina. J Am Coll Cardiol. 2002;39(1):37-45.

17. Deaton C, Kimble LP, Veledar E, et al. The synergistic effect of heart disease and diabetes on self-management, symptoms, and health status. Heart Lung. 2006;35(5):315-323.

18. Andrell P, Ekre O, Grip L, et al. Fatality, morbidity and quality of life in patients with refractory angina pectoris. Int J Cardiol. 2011;147(3): 377-382.

19. Lowe HC, Oesterle SN, He KL, MacNeill BD, Burkhoff D. Outcomes following percutaneous coronary intervention in patients previously considered "without option": a subgroup analysis of the PACIFIC trial. J Interv Cardiol. 2004;17(2):87-91.

20. Ohldin A, Young B, Derleth A, et al. Ethnic differences in satisfaction and quality of life in veterans with ischemic heart disease. J Natl Med Assoc. 2004;96(6):799-808.

21. Neil N, Ramsey SD, Cohen DJ, et al. Resource utilization, cost, and health status impacts of coronary stent versus "optimal" percutaneous coronary angioplasty: results from the OPUS-I trial. J Interv Cardiol. 2002;15(4):249-255. 
22. Pettersen KI, Reikvam A, Stavem K. Reliability and validity of the Norwegian translation of the Seattle Angina Questionnaire following myocardial infarction. Qual Life Res. 2005;14(3):883-889.

23. Gelsomino S, Lorusso R, Livi U, et al. Cost and cost-effectiveness of cardiac surgery in elderly patients. J Thorac Cardiovasc Surg. 2011;142(5):1062-1073

24. Fathi R, Haluska B, Short L, Marwick TH. A randomized trial of aggressive lipid reduction for improvement of myocardial ischemia, symptom status, and vascular function in patients with coronary artery disease not amenable to intervention. Am J Med. 2003;114(6):445-453.

25. Moore RK, Groves D, Bateson S, et al. Health related quality of life of patients with refractory angina before and one year after enrolment onto a refractory angina program. Eur J Pain. 2005;9(3):305-310.

26. Graham MM, Norris CM, Galbraith PD, Knudtson ML, Ghali WA; APPROACH Investigators. Quality of life after coronary revascularization in the elderly. Eur Heart J. 2006;27(14):1690-1698.

27. Agarwal S, Schechter C, Zaman A. Assessment of functional status and quality of life after percutaneous coronary revascularisation in octogenarians. Age Ageing. 2009;38(6):748-751.

28. MacDonald P, Stadnyk K, Cossett J, Klassen G, Johnstone D, Rockwood K. Outcomes of coronary artery bypass surgery in elderly people. Can J Cardiol. 1998;14(10):1215-1222.

29. Fruitman DS, MacDougall CE, Ross DB. Cardiac surgery in octogenarians: can elderly patients benefit? Quality of life after cardiac surgery. Ann Thorac Surg. 1999;68(6):2129-2135.

30. Broddadottir H, Jensen L, Norris C, Graham M. Health-related quality of life in women with coronary artery disease. Eur J Cardiovasc Nurs. 2009;8(1):18-25.

31. Bainey KR, Norris CM, Gupta M, et al. Altered health status and quality of life in South Asians with coronary artery disease. Am Heart J. 2011;162(3):501-506.

32. Ascione R, Reeves BC, Taylor FC, Seehra HK, Angelini GD. Beating heart against cardioplegic arrest studies (BHACAS 1 and 2): quality of life at mid-term follow-up in two randomised controlled trials. Eur Heart J. 2004;25(9):765-770.

33. Angelini GD, Culliford L, Smith DK, et al. Effects of on- and off-pump coronary artery surgery on graft patency, survival, and health-related quality of life: long-term follow-up of 2 randomized controlled trials. J Thorac Cardiovasc Surg. 2009;137(2):295-303.

34. Karolak W, Hirsch G, Buth K, Legare JF. Medium-term outcomes of coronary artery bypass graft surgery on pump versus off pump: results from a randomized controlled trial. Am Heart J. 2007;153(4):689-695.

35. Chaudhury S, Sharma S, Pawar AA, et al. Psychological correlates of outcome after coronary artery bypass graft. Med J Armed Forces India. 2006;62(3):220-223

36. Wagner TH, Sethi G, Holman W, et al. Costs and quality of life associated with radial artery and saphenous vein cardiac bypass surgery: results from a Veterans Affairs multisite trial. Am J Surg. 2011;202(5): 532-535

37. de Quadros AS, Lima TC, Rodrigues AP, et al. Quality of life and health status after percutaneous coronary intervention in stable angina patients: results from the real-world practice. Catheter Cardiovasc Interv. 2011;77(7):954-960.

38. Wong MS, Chair SY. Changes in health-related quality of life following percutaneous coronary intervention: a longitudinal study. Int J Nurs Stud. 2007;44(8):1334-1342.

39. Weintraub WS, Spertus JA, Kolm P, et al. Effect of PCI on quality of life in patients with stable coronary disease. NEngl J Med. 2008;359(7): $677-687$.
40. Rumsfeld JS, Alexander KP, Goff DC Jr, et al. Cardiovascular health: the importance of measuring patient-reported health status: a scientific statement from the American Heart Association. Circulation. 2013;127(22):2233-2249.

41. Mommersteeg PM, Denollet J, Spertus JA, Pedersen SS. Health status as a risk factor in cardiovascular disease: a systematic review of current evidence. Am Heart J. 2009;157(2):208-218.

42. Heidenreich PA, Spertus JA, Jones PG, et al. Health status identifies heart failure outpatients at risk for hospitalization or death. J Am Coll Cardiol. 2006;47(4):752-756.

43. Chan PS, Soto G, Jones PG, et al. Patient health status and costs in heart failure: insights from the eplerenone post-acute myocardial infarction heart failure efficacy and survival study (EPHESUS). Circulation. 2009;119(3):398-407

44. National Institute for Health and Clinical Excellence. Briefing Paper for Methods Review Workshop on Key Issues in Utility Measurement. London, UK: National Institute for Health and Clinical Excellence; 2007.

45. Brazier JE, Yang Y, Tsuchiya A, Rowen DL. A review of studies mapping (or cross walking) non-preference based measures of health to generic preference-based measures. Eur J Health Econ. 2010;11(2): 215-225.

46. Dyer MT, Goldsmith KA, Sharples LS, Buxton MJ. A review of health utilities using the EQ-5D in studies of cardiovascular disease. Health Qual Life Outcomes. 2010;8:13.

47. Leung YW, Grewal K, Gravely-Witte S, Suskin N, Stewart DE, Grace SL. Quality of life following participation in cardiac rehabilitation programs of longer or shorter than 6 months: does duration matter? Population Health Management. 2011;14(4):181-188.

48. Zhang Z, Mahoney EM, Stables RH, et al. Disease-specific health status after stent-assisted percutaneous coronary intervention and coronary artery bypass surgery: one-year results from the Stent or Surgery trial. Circulation. 2003;108(14):1694-1700.

49. Kim J, Henderson RA, Pocock SJ, et al. Health-related quality of life after interventional or conservative strategy in patients with unstable angina or non-ST-segment elevation myocardial infarction: one-year results of the third Randomized Intervention Trial of unstable Angina (RITA-3). J Am Coll Cardiol. 2005;45(2):221-228.

50. Hofer S, Benzer W, Schussler G, von Steinbuchel N, Oldridge NB. Health-related quality of life in patients with coronary artery disease treated for angina: validity and reliability of German translations of two specific questionnaires. Qual Life Res. 2003;12(2):199-212.

51. Arnold SV, Morrow DA, Wang K, et al; MERLIN-TIMI 36 Investigators. Effects of ranolazine on disease-specific health status and quality of life among patients with acute coronary syndromes: results from the MERLIN-TIMI 36 randomized trial. Circ Cardiovasc Qual Outcomes. 2008;1(2):107-115.

52. Arnold SV, Spertus JA, Jones PG, Xiao L, Cohen DJ. The impact of dyspnea on health-related quality of life in patients with coronary artery disease: results from the PREMIER registry. Am Heart $J$. 2009;157(6):1042-1049. e1041.

53. Asadi-Lari M, Packham C, Gray D. Gender difference in health-related needs and quality of life in patients with acute chest pain. Br J Cardiol. 2005;12(6):459-464.

54. de Jong-Watt WJ, Arthur HM. Anxiety and health-related quality of life in patients awaiting elective coronary angiography. Heart \& Lung. 2004;33(4):237-248. 


\section{Supplementary material}

The following method describes the search strategy used to collect the references analyzed in this study. This strategy had three primary facets, outlined below.

- Identification of materials in the primary databases of medical literature that referenced the Seattle Angina Questionnaire. These databases were MEDLINE (Ovid), EMBASE (Elsevier), OVID HealthStar, MEDLINE (PubMed), and the Cochrane Library (Wiley).

- Use of the citation mapping tools Google Scholar (Google), Scopus (Elsevier), and Web of Science (Thomson Reuters), to find all available references to the paper in which Seattle Angina Questionnaire was first described by John Spertus et al in the Journal of the American College of Cardiology in 1995. The search strategy was to locate the original article by Spertus et al and export the references that the tool identified as having cited that article.

- Use of the major clinical trial registries to determine the studies that used the SAQ as an outcome measure. These registries have simple search functions, and so our search terms were "Seattle Angina Questionnaire" or "SAQ". The strategy then underwent peer review by a librarian experienced in the creation and review of systematic search strategies.

\section{Search strategy}

The following search strategy was applied to MEDLINE (Ovid), HealthStar (Ovid), and EMBASE (Ovid). It was adapted for use in PubMed by updating the syntax to match that offered in the PubMed search tool. When searching the Cochrane Library, only the words "Seattle Angina Questionnaire" were used. Databases were searched from inception until 2013.

1. (Development and evaluation of the Seattle Angina Questionnaire: a new functional status measure for coronary artery disease).m_titl.

2. seattle angina questionnaire.mp.

3. seattle angina questionnaire.tw.

4. (seattle adj3 angina).af.

5. (angina adj3 questionnaire).af.

6. saq.mp.

7. or/1-6.

8. spertus ja.au.

9. 7 and 8 .

\section{Publish your work in this journal}

ClinicoEconomics \& Outcomes Research is an international, peerreviewed open-access journal focusing on Health Technology Assessment, Pharmacoeconomics and Outcomes Research in the areas of diagnosis, medical devices, and clinical, surgical and pharmacological intervention. The economic impact of health policy and health systems organization also constitute important areas of coverage. The manuscript management system is completely online and includes a very quick and fair peer-review system, which is all easy to use. Visit http://www.dovepress.com/testimonials.php to read real quotes from published authors. 